\title{
Impact of splenic hilar lymph node metastasis on prognosis in patients with advanced gastric cancer
}

\author{
Taeil Son ${ }^{1,2}$, In Gyu Kwon ${ }^{3}$, Joong Ho Lee ${ }^{4}$, Youn Young Choi ${ }^{1,2}$, Hyoung-Il Kim ${ }^{1,2}$, \\ Jae-Ho Cheong ${ }^{1,2}$, Sung Hoon Noh $^{1,2}$ and Woo Jin Hyung ${ }^{1,2}$ \\ ${ }^{1}$ Department of Surgery, Yonsei University College of Medicine, Seoul, South Korea \\ ${ }^{2}$ Gastric Cancer Center, Yonsei Cancer Center, Seoul, South Korea \\ ${ }^{3}$ Department of Surgery, Keimyung University School of Medicine, Daegu, South Korea \\ ${ }^{4}$ Department of Surgery, National Health Insurance Service Ilsan Hospital, Goyang, South Korea \\ Correspondence to: Woo Jin Hyung, email: wjhyung@yuhs.ac \\ Keywords: gastric cancer, D2 lymphadenectomy, splenic hilar lymph node, prognosis \\ Received: February 15, 2017 Accepted: June 10, $2017 \quad$ Published: June 28, 2017 \\ Copyright: Son et al. This is an open-access article distributed under the terms of the Creative Commons Attribution License 3.0 (CC BY \\ $3.0)$, which permits unrestricted use, distribution, and reproduction in any medium, provided the original author and source are credited.
}

\section{ABSTRACT}

Background: Impact of splenic hilar LN dissection during total gastrectomy for proximal advanced gastric cancer is controversial. The objective of this study was to assess the impact on prognosis of splenic hilar lymph node(LN) metastasis compared to that of metastasis to other regional LN groups.

Study Design: Patients who underwent total gastrectomy with D2 LN dissection from $\mathbf{2 0 0 0}$ to $\mathbf{2 0 1 0}$ were reviewed retrospectively. The clinicopathologic characteristics and long-term results of patients with splenic hilar LN metastasis were compared to those of patients with only metastasis to other extraperigastric LNs (stations \#8a, \#9, \#11, or \#12a). To investigate the survival benefit of performing splenic hilar LN dissection, the estimated therapeutic index for the procedure was calculated by multiplying the incidence of metastases in the hilar region by the survival rates for individuals with nodal involvement in that region.

Results: Of 602 patients, $87(14.5 \%)$ had hilar LN metastasis. The 5-year overall and relapse-free survival rates for patients with hilar LN metastasis were $24.1 \%$ and $12.1 \%$, respectively. These rates were similar to those for patients with metastasis to other extraperigastric LNs $(P>0.05)$, with similar recurrence patterns. Overall survival in the hilar LN metastasis group was better than that for patients with distant metastasis $(P<0.05)$. The estimated therapeutic index of splenic hilar $\mathrm{LN}$ dissection was 3.5, which was similar to index values for LN dissection at other extraperigastric LNs.

Conclusions: Dissection of splenic hilar LNs during total gastrectomy for advanced gastric cancer allows for a prognosis similar to that achieved with dissection of extraperigastric LNs.

\section{INTRODUCTION}

Gastric cancer is the fifth most common malignancy and the third leading cause of cancer death in the world [1]. Most gastric cancer is initially diagnosed at the advanced disease stage except in countries that have mass-screening programs [1-5]. Although the incidence of gastric cancer worldwide has remained steady, increases in proximal gastric cancers, including esophagogastric junction cancer [6], have bolstered recommendations for performing total gastrectomy with $\mathrm{D} 2$ lymph node (LN) dissection for proximal advanced gastric cancer [7-9].

The reported incidence of metastasis to splenic hilar LNs in proximal gastric cancer ranges from 5.8 to $26.7 \%$ [10-16]. Thus, most treatment guidelines for proximal gastric cancer recommend dissection of the splenic hilar LNs as a regional LN group during total gastrectomy with D2 LN dissection [7-9]. To accomplish this dissection, surgeons typically perform either a splenectomy or a spleen-preserving technique. Although splenectomies 
have been found to be associated with high morbidity and mortality, spleen-preserving hilar LN dissection can be technically demanding [15-18], and therefore surgeons are reluctant to perform splenic hilar LN dissection during total gastrectomy for proximal advanced gastric cancer. More importantly, the prognostic impact of metastasis to the splenic hilar LNs has yet to be determined, obscuring the necessity of performing splenic hilar LN dissection during gastrectomy.

The aim of this study was to assess the impact of splenic hilar LN metastasis on prognosis in gastric cancer patients via comparison of the recurrence patterns and overall and relapse-free survival rates in cases of splenic hilar LN metastasis with those in cases of metastasis to other regional LNs. We also compared overall survival for splenic hilar LN metastasis with that for distant metastasis. Lastly, we calculated and compared estimated therapeutic index values for splenic hilar LN dissection and dissection of other regional LNs.

\section{RESULTS}

\section{Patient demographics}

Of the 602 patients who underwent total gastrectomy with D2 LN dissection, 258 patients received a splenectomy, and 344 patients received splenic hilar LN dissection without splenectomy. Among gastrectomy patients, 87 (14.5\%) had hilar LN metastasis, and 515 $(85.5 \%)$ had no hilar LN metastasis. The mean age of the LN \#10-positive group versus the LN \#10-negative group was 54.9 y versus 56.6 y $(p=0.225)$, with $52(59.8 \%)$ versus $351(68.2 \%)$ male patients $(p=0.124)$ in each group, respectively. Tumors from LN \#10-positive patients showed undifferentiated histology more frequently $(p=0.002)$, were of larger size $(p<0.001)$, were more frequently found in the greater curvature of the stomach or as an encircling lesion $(p<0.001)$, comprised more Borrmann type IV cancers $(p<0.001)$, and exhibited more frequent lympho-vascular involvement $(p<0.001)$ than tumors from LN \#10-negative patients. Although the mean number of retrieved LNs in the LN \#10-positive group did not differ from that in the LN \#10-negative group (56.1 vs. 52.3, $p=0.063$ ), the mean number of metastatic LNs was significantly greater (25.5 vs. 7.0, $p<0.001$ ) in the LN \#10-positive group. As expected, LN \#10-positive patients had more advanced $\mathrm{T}$, $\mathrm{N}$, and TNM stage cancers than LN \#10-negative patients $(p<0.001$ for all comparisons; Table 1$)$.

Clinicopathologic characteristics were compared between groups with metastasis to other extraperigastric LNs stations (stations \#8a, \#9, \#11, or \#12a) but not to the splenic hilar LNs, and subgroups of patients with metastasis to the hilar LN \#10 but not to each of the other stations. In this comparison, there was no patient with metastasis to LN \#10 but not to other extraperigastric LN. The LN \#10-positive subgroups had more advanced pathologic $\mathrm{T}$ classifications than any extraperigastric, LN \#8a-, LN \#9-, and LN \#12a-positive groups ( $p<0.001$, $0.011,0.037$, and $<0.001$, respectively). The number of metastatic LNs and $\mathrm{N}$ classifications of the LN \#10-positive subgroups, however, were similar to those for the LN \#8a-, LN \#9-, LN \#11-, and LN \#12a-positive groups. Overall, the LN \#10-positive subgroup patients showed more advanced stage disease than any extraperigastric, LN \#8a-, LN \#9-, and LN \#12a-positive patients but not LN \#11-positive patients (Table 2).

\section{Oncologic outcomes and survival analyses}

Long-term follow-up over a median of 89 months revealed significant differences in overall survival between LN \#10-positive patients and LN \#10-negative patients (5-year overall survival of $24.1 \%$ vs. $54.8 \%$, respectively, $p<0.001)$. Meanwhile, no significant differences in overall survival were found between patients in the LN \#10 subgroups and those with metastasis to LN \#8a, LN \#9, LN \#11, or LN \#12a (5-year overall survival of $24.1 \%$ vs. $28.0 \%, p=0.524 ; 28.1 \%$ vs. $26.4 \%, p=0.737 ; 22.5 \%$ vs. $19.5 \%, p=0.409$; and $23.5 \%$ vs. $14.3 \%, p=0.970$, respectively). Overall survival in the LN \#10-positive group was, however, better than that of LN \#10-positive patients with distant metastasis (M1) and that of patients with distant metastasis but no LN \#10 metastasis ( $p=0.006$ and $p=0.014$, respectively; Figure 1 ).

With regard to relapse-free survival, LN \#10-positive subgroup patients experienced survival similar to that in LN \#8a-, LN \#9-, LN \#11-, and LN \#12a-positive patients (5-year relapse-free survival of $17.2 \%$ vs. $20.2 \%$, $p=0.737 ; 16.0 \%$ vs. $17.0 \%, p=0.916 ; 19.8 \%$ vs. $9.4 \%$, $p=0.426$; and $12.6 \%$ vs. $7.9 \%, p=0.444$, respectively; Figure 2). Recurrence patterns in $\mathrm{LN} \# 10$-positive patients were also similar to those in LN \#8a-, LN \#9-, LN \#11-, and LN \#12a-positive patients $(p=0.596,0.134,0.712$, and 0.085 , respectively; Table 3 ). The most common pattern of recurrence was peritoneal recurrence, regardless of involvement at any other extraperigastric LN station.

\section{Therapeutic index of lymph node dissection at each lymph node station after total gastrectomy with D2 lymph node dissection}

The incidences of metastasis and the 5-year overall survival rates for each LN station are provided in Figure 3. The incidences of LN metastasis at LN \#8a, LN \#9, LN $\# 11$, and LN \#12a were 14.0\%, 16.1\%, 13.0\%, and 2.7\%, respectively. The incidence of metastasis to the splenic hilar LNs was $14.5 \%$. The therapeutic index values of the estimated benefit of dissection of perigastric LN stations (stations \#1 to \#7) ranged from 2.6 to 20.7. The therapeutic index values for dissection of extraperigastric LNs (stations \#8a, \#9, \#11, and \#12a) ranged from 0.5 to 3.8. The estimated therapeutic value of splenic hilar LN 
Table 1: Clinicopathologic factors for patients classified according to metastasis to lymph node station 10

\begin{tabular}{|c|c|c|c|c|c|c|c|}
\hline \multirow{2}{*}{ Variable } & \multicolumn{3}{|c|}{$\begin{array}{c}\text { LN\#10 (+) } \\
(n=87)\end{array}$} & \multicolumn{3}{|c|}{$\begin{array}{l}\text { LN\#10 (-) } \\
(n=515)\end{array}$} & \multirow{2}{*}{$P^{*}$} \\
\hline & $\begin{array}{c}\text { No. of } \\
\text { Patients }\end{array}$ & & $\%$ & $\begin{array}{c}\text { No. of } \\
\text { Patients }\end{array}$ & & $\%$ & \\
\hline Age, years & & & & & & & 0.225 \\
\hline Mean & & 54.9 & & & 56.6 & & \\
\hline SD & & 13.1 & & & 12.2 & & \\
\hline Sex & & & & & & & 0.124 \\
\hline Male & 52 & & 59.8 & 351 & & 68.2 & \\
\hline Female & 35 & & 40.2 & 164 & & 31.8 & \\
\hline Splenectomy & & & & & & & $<0.001$ \\
\hline Yes & 56 & & 64.4 & 204 & & 39.6 & \\
\hline No & 31 & & 35.6 & 311 & & 60.4 & \\
\hline Operation procedure & & & & & & & 0.407 \\
\hline Open & 85 & & 97.7 & 489 & & 95.0 & \\
\hline Minimally invasive & 2 & & 2.3 & 26 & & 5.0 & \\
\hline Histologic type & & & & & & & 0.002 \\
\hline Differentiated & 10 & & 11.5 & 137 & & 26.6 & \\
\hline Undifferentiated & 77 & & 88.5 & 378 & & 73.4 & \\
\hline Tumor size, $\mathrm{cm}$ & & & & & & & $<0.001$ \\
\hline Mean & & 87.1 & & & 64.2 & & \\
\hline SD & & 43.1 & & & 33.8 & & \\
\hline Location & & & & & & & $<0.001$ \\
\hline $\mathrm{LC}$ & 28 & & 32.2 & 260 & & 50.5 & \\
\hline $\mathrm{GC}$ & 19 & & 21.8 & 47 & & 9.1 & \\
\hline AW & 14 & & 16.1 & 76 & & 14.8 & \\
\hline PW & 17 & & 19.5 & 121 & & 23.5 & \\
\hline Circular & 9 & & 10.4 & 11 & & 2.1 & \\
\hline Gross type & & & & & & & $<0.001$ \\
\hline Borrmann I & 4 & & 4.6 & 34 & & 6.6 & \\
\hline Borrmann II & 8 & & 9.2 & 116 & & 22.5 & \\
\hline Borrmann III & 38 & & 43.7 & 252 & & 48.9 & \\
\hline Borrmann IV & 35 & & 40.2 & 108 & & 21.0 & \\
\hline Borrmann V & 2 & & 2.3 & 5 & & 1.0 & \\
\hline LV invasion & & & & & & & $<0.001$ \\
\hline negative & 7 & & 8.0 & 195 & & 37.9 & \\
\hline positive & 80 & & 92.0 & 320 & & 62.1 & \\
\hline Number of metastatic LNs & & & & & & & $<0.001$ \\
\hline Mean & & 25.5 & & & 7.0 & & \\
\hline SD & & 18 & & & 10.2 & & \\
\hline
\end{tabular}




$$
\text { Mean }
$$

SD

56.1

17.7

T classification

$\mathrm{T} 2$

T3

T4a

$\mathrm{T} 4 \mathrm{~b}$

$\mathrm{N}$ classification

N0

N1

N2

N3

TNM stage

Stage IB

Stage IIA

Stage IIB

Stage IIIA

Stage IIIB

Stage IIIC
2

6

67

12

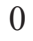

2

8

77

0

0

3

0

11

73
52.3

17.9

$<0.001$

12.0

23.5

61.6

2.9

$<0.001$

27.8

16.5

20.8

35.0

$<0.001$

7.2

10.7

17.1

16.3

19.6

29.1

Abbreviations: LN, lymph node; SD, standard deviation; LC, lesser curvature; GC, greater curvature; AW, anterior wall; PW, posterior wall; LV, lympho-vascular. * $P$-values were determined for Student's $t$-test or $\chi^{2}$ (Fisher's exact) test for continuous or categorical factors, respectively.

dissection was 3.5 and was calculated as follows: [0.145 (incidence of splenic hilar LN metastasis) $\times 24.1$ (5-year overall survival)]. Thus, the therapeutic index value of splenic hilar LN dissection was within the range of therapeutic index values for dissection of extraperigastric LN stations.

\section{DISCUSSION}

The prognosis for advanced gastric cancer patients with splenic hilar LN metastasis in the current study was similar to that for patients with any extraperigastric LN metastasis and better than that for those with distant metastasis. Relapse-free survival and patterns of recurrence in the patients with splenic hilar LN metastasis were also comparable to patients with other extraperigastric LN metastasis. Additionally, calculation of the therapeutic index of splenic hilar LN dissection during total gastrectomy for the treatment of proximal advanced gastric cancer revealed that the procedure had an impact on patient survival similar to dissection of other extraperigastric LNs.

Although current treatment guidelines recommend splenic hilar LN dissection during total gastrectomy with D2 LN dissection, the prognosis of patients with splenic hilar LN metastasis is poor. The discovery that hilar LN metastasis exhibits a similar prognosis to para-aortic LN metastasis spurred some investigators to raise questions regarding the stratification of splenic hilar $\mathrm{LN}$ as a extraperigastric LN and to suggest reclassifying splenic hilar LNs as a distant LN group [11]. In another study, the 5-year survival rate of patients with splenic hilar LN metastasis was significantly low at around 5\%, even after curative total gastrectomy with D2 LN dissection, and was similar to that of patients undergoing R1 or R2 resection. Accordingly, the authors expressed doubts about the therapeutic impact of removing the splenic hilar LNs, suggesting that no benefit exists [14]. Meanwhile, however, other investigators reported that in the presence of curative surgery, the survival of hilar LN-positive patients did not differ from that of hilar LN-negative patients, and therefore, these investigators supported recommendations for D2 lymphadenectomy including splenic hilar LN dissection [19]. Similarly, in the present study, the 5-year overall survival of patients with splenic hilar LN metastasis was $24.1 \%$ and better than that in patients with distant metastasis. In addition, the survival of patients with splenic hilar LN metastasis was similar to patients with other extraperigastric LN metastasis, 
A

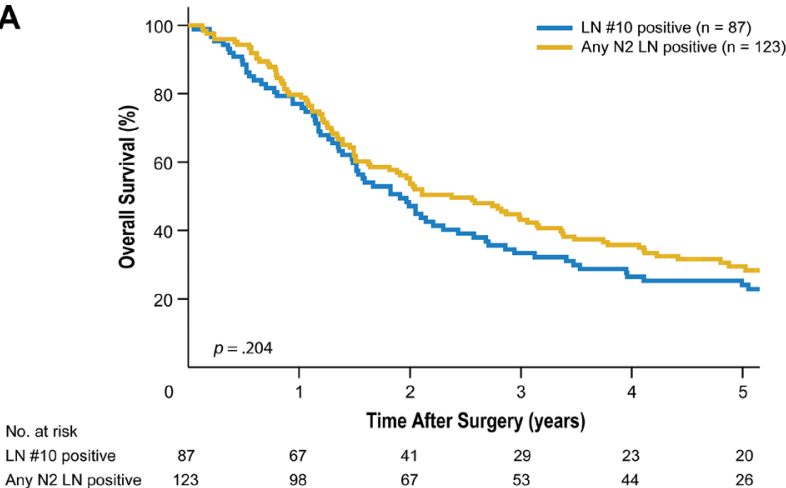

C

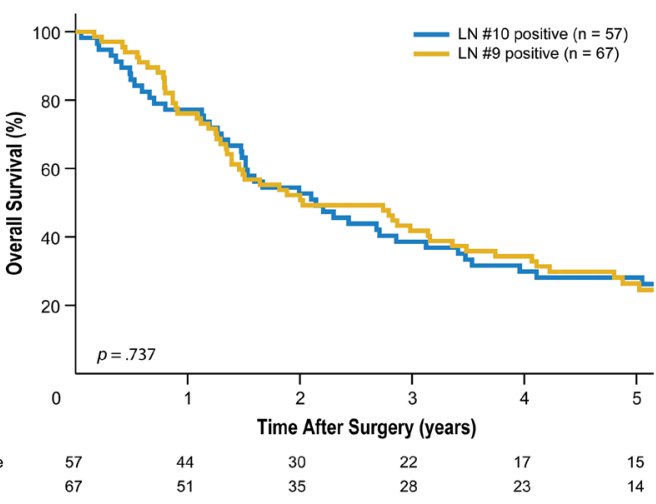

E

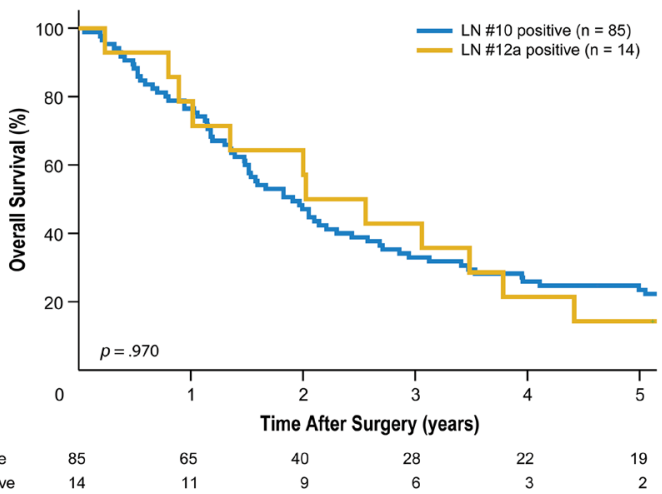

B

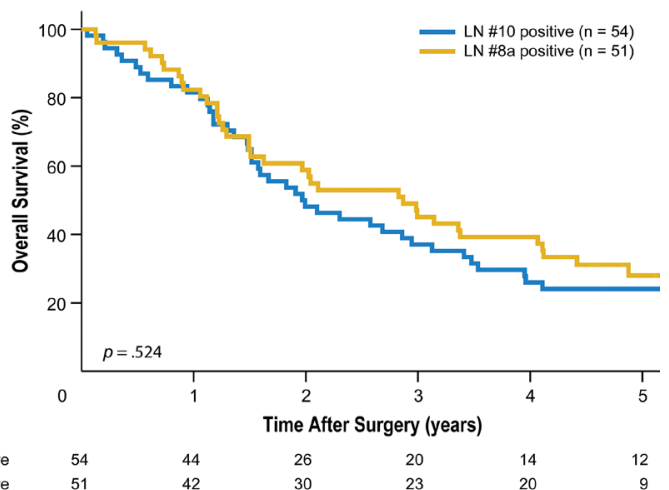

D

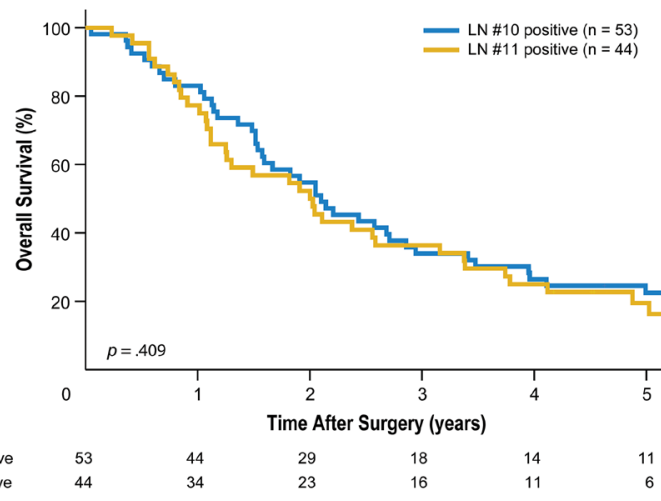

$\mathbf{F}$

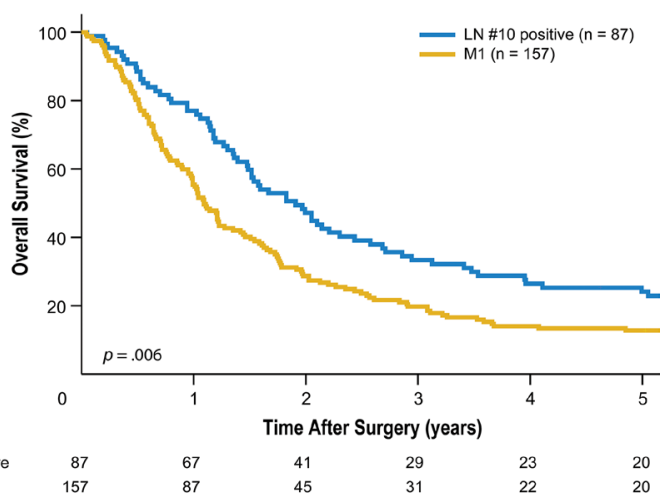

G

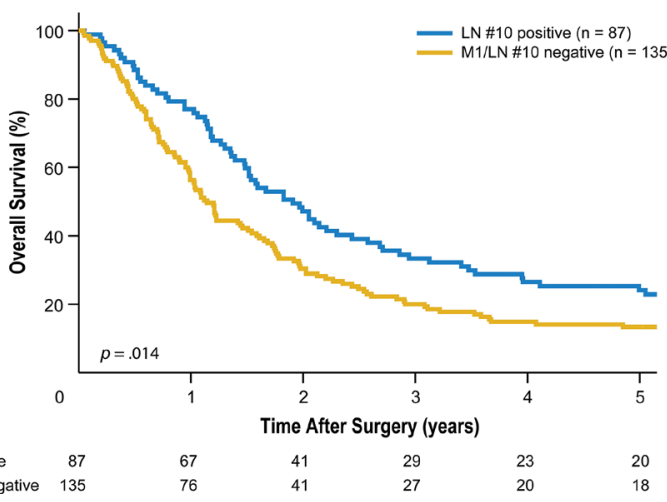

Figure 1: Kaplan-Meier overall survival curves for patients with splenic hilar lymph node (LN) metastasis compared to those with metastasis to extraperigastric LNs. (A) Compared to metastasis to any extraperigastric LN $(P=0.204)$. (B) Compared to LN \#8a metastasis $(P=0.524)$. (C) Compared to LN \#9 metastasis $(P=0.737)$. (D) Compared to LN \#11 metastasis $(P=0.409)$. (E) Compared to LN \#12a metastasis. $(P=0.970)$. (F) Compared to distant metastasis $(\mathrm{M} 1)(P=0.006)$. (G) Compared to M1 excluding LN \#10 metastasis $(P=0.014)$. 
although the survival of patients with extraperigastric LN metastasis in this study remained poor. The poor survival rates in this study likely stem from the large number of metastatic LNs in the patients, who were stratified as having $\mathrm{N} 3 \mathrm{~b}$ disease according to current gastric cancer staging systems [20]. Moreover, around 73.6\% (64 of 87 patients) of the patients experienced recurrence during follow-up after receiving curative treatment. The discrepancies between studies on the benefits of splenic hilar LN dissection probably stem from differences in the
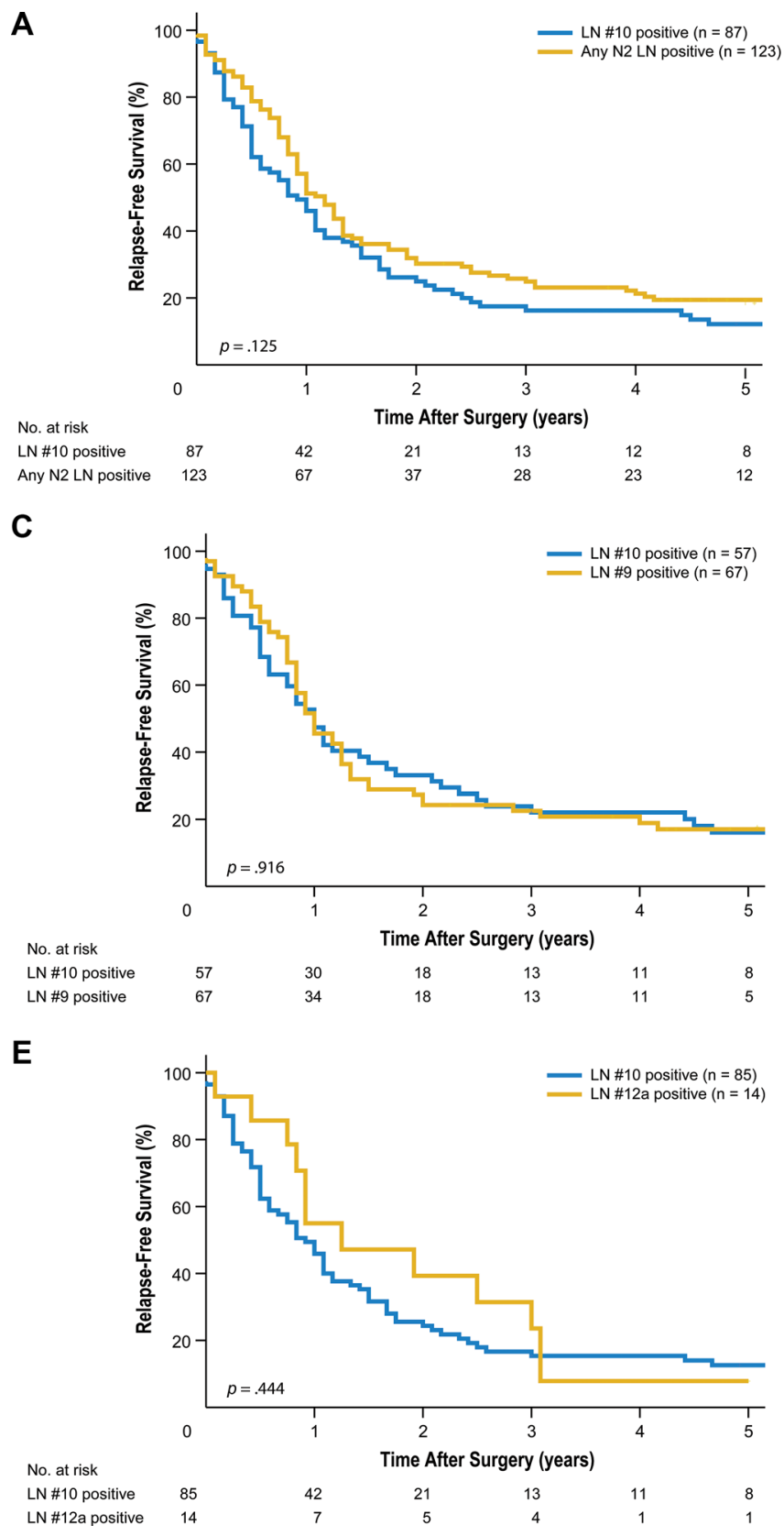

number of patients with LN \#10 metastasis in the studies. Therefore, only small numbers of patients were included in the survival comparisons $[10,11,14,16]$. In the current study, however, we included 87 patients with LN \#10 metastasis without M1 disease, thereby allowing us to conduct a more comprehensive analysis.

As the prognosis of splenic hilar LN metastasis is still under debate, we sought to investigate whether classification of splenic hilar LNs as a regional LN group is appropriate. Thus, we conducted a unique comparison

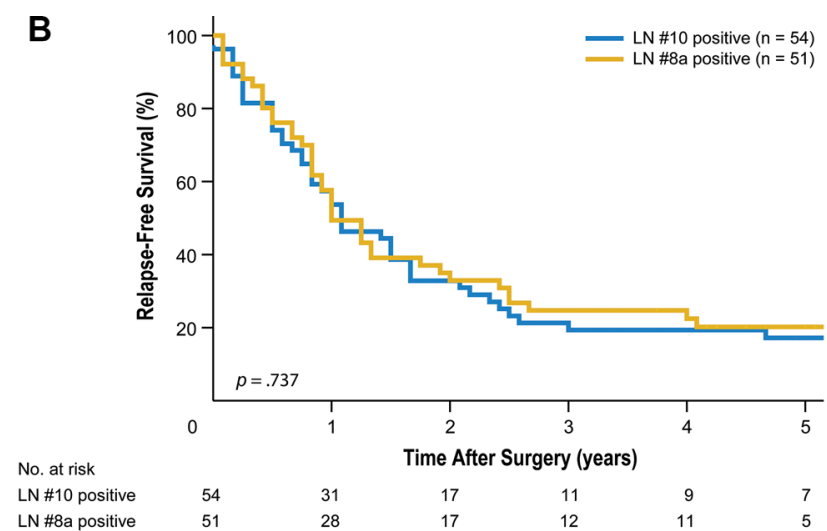

D

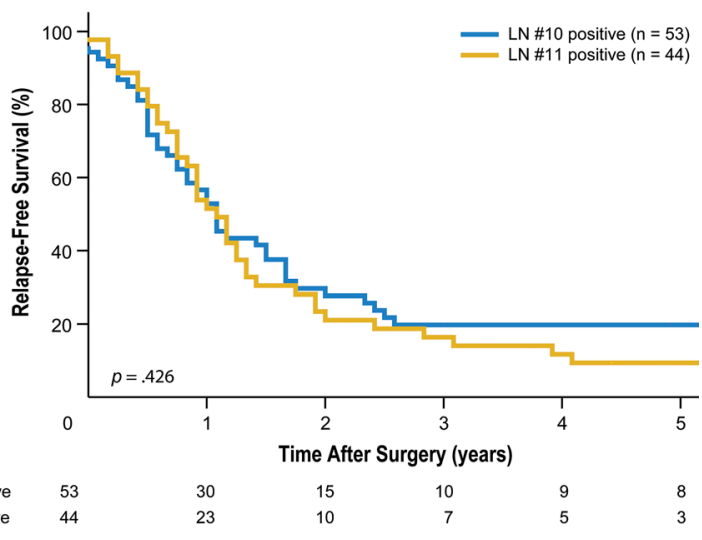

Figure 2: Kaplan-Meier relapse-free survival curves for patients with splenic hilar lymph node (LN) metastasis compared to those with metastasis to extraperigastric LNs. (A) Compared to metastasis to any extraperigastric $\mathrm{LN}(P=0.125)$. (B) Compared to LN \#8a metastasis $(P=0.737)$. (C) Compared to LN \#9 metastasis $(P=0.916)$. (D) Compared to LN \#11 metastasis $(P=0.426)$. (E) Compared to LN \#12a metastasis $(P=0.444)$. 
Table 2: Clinicopathologic factors of patients with metastasis to lymph node station 10 in comparison to patients with exclusive metastasis to other extraperigastric LN stations

\begin{tabular}{|c|c|c|c|c|c|c|c|c|c|c|c|c|c|c|c|}
\hline & $\begin{array}{c}\text { LN\#10(+) } \\
(n=87)\end{array}$ & $\begin{array}{c}\text { LN\#10(-) } \\
\text { any } N 2(+) \\
(n=123)\end{array}$ & & $\begin{array}{c}\text { LN\#10(+) } \\
\text { LN\#8a(-) } \\
(n=54)\end{array}$ & $\begin{array}{c}\text { LN\#10(-) } \\
\text { LN\#8a(+) } \\
(n=51)\end{array}$ & & $\begin{array}{c}\text { LN\#10(+) } \\
\text { LN\#9(-) } \\
(n=57)\end{array}$ & $\begin{array}{c}\text { LN\#10(-) } \\
\text { LN\#9 (+) } \\
(n=67)\end{array}$ & & $\begin{array}{c}\text { LN\#10(+) } \\
\text { LN\#11(-) } \\
(n=53)\end{array}$ & $\begin{array}{c}\text { LN\#10(-) } \\
\text { LN\#11(+) } \\
(n=44)\end{array}$ & & $\begin{array}{c}\text { LN\#10(+) } \\
\text { LN\#12a(-) } \\
(n=85)\end{array}$ & $\begin{array}{c}\text { LN\#10 (-) } \\
\text { LN\#12a (+) } \\
(n=14)\end{array}$ & \\
\hline & $\begin{array}{c}\text { No. of } \\
\text { Patients } \\
(\%)\end{array}$ & $\begin{array}{c}\text { No. of } \\
\text { Patients } \\
(\%)\end{array}$ & $P^{*}$ & $\begin{array}{c}\text { No. of } \\
\text { Patients } \\
(\%)\end{array}$ & $\begin{array}{c}\text { No. of } \\
\text { Patients } \\
(\%)\end{array}$ & $P^{*}$ & $\begin{array}{c}\text { No. of } \\
\text { Patients } \\
(\%)\end{array}$ & $\begin{array}{c}\text { No. of } \\
\text { Patients } \\
(\%)\end{array}$ & $P^{*}$ & $\begin{array}{c}\text { No. of } \\
\text { Patients } \\
(\%)\end{array}$ & $\begin{array}{c}\text { No. of } \\
\text { Patients } \\
(\%)\end{array}$ & $P^{*}$ & $\begin{array}{c}\text { No. of } \\
\text { Patients (\%) }\end{array}$ & $\begin{array}{c}\text { No. of } \\
\text { Patients } \\
(\%)\end{array}$ & $P^{*}$ \\
\hline Histologic type & & & 0.031 & & & 0.056 & & & 0.142 & & & $>0.999$ & & & $<0.001$ \\
\hline Differentiated & $10(11.5)$ & $29(23.6)$ & & $6(11.1)$ & $13(25.5)$ & & $7(12.3)$ & $15(22.4)$ & & $3(5.7)$ & $3(6.8)$ & & $9(10.6)$ & $8(57.1)$ & \\
\hline Undifferentiated & $77(88.5)$ & 94 (76.4) & & 48 (88.9) & $38(74.5)$ & & $50(87.7)$ & $52(77.6)$ & & $50(94.3)$ & $41(93.2)$ & & $76(89.4)$ & $6(42.9)$ & \\
\hline Tumor size, mm & & & 0.014 & & & 0.002 & & & 0.422 & & & 0.662 & & & 0.298 \\
\hline Mean & 87.1 & 73.1 & & 86.4 & 65.4 & & 81.7 & 75.9 & & 80.3 & 77.2 & & 87.2 & 74.6 & \\
\hline SD & 43.1 & 35.9 & & 41.5 & 23.8 & & 39.3 & 41.4 & & 38.7 & 30.0 & & 43.3 & 29.9 & \\
\hline Location & & & 0.003 & & & 0.002 & & & 0.048 & & & 0.101 & & & 0.569 \\
\hline $\mathrm{LC}$ & $28(32.2)$ & $67(54.5)$ & & $17(31.5)$ & $32(62.7)$ & & $19(33.3)$ & $35(52.2)$ & & $16(30.2)$ & $23(52.3)$ & & $27(31.8)$ & $6(42.9)$ & \\
\hline $\mathrm{GC}$ & $19(21.8)$ & $12(9.8)$ & & $13(24.1)$ & $3(5.9)$ & & $12(21.1)$ & $11(16.4)$ & & $14(26.4)$ & $4(9.1)$ & & $19(22.3)$ & $1(7.1)$ & \\
\hline $\mathrm{AW}$ & $14(16.1)$ & $18(14.6)$ & & $9(16.7)$ & $6(11.8)$ & & $10(17.5)$ & $12(17.9)$ & & $11(20.8)$ & $6(13.6)$ & & $14(16.5)$ & $4(28.6)$ & \\
\hline PW & 17 (19.6) & $23(18.7)$ & & $10(18.5)$ & $10(19.6)$ & & $11(19.3)$ & $9(13.4)$ & & $8(15.1)$ & $8(18.2)$ & & $16(18.8)$ & $2(14.3)$ & \\
\hline Circular & $9(10.3)$ & $3(2.4)$ & & $5(9.2)$ & $0(0)$ & & $5(8.8)$ & $0(0)$ & & $4(7.5)$ & $3(6.8)$ & & $9(10.6)$ & $1(7.1)$ & \\
\hline $\begin{array}{l}\text { Number } \\
\text { metastatic LN }\end{array}$ & & & $<0.001$ & & & 0.207 & & & 0.125 & & & 0.716 & & & 0.135 \\
\hline Mean & 25.5 & 15.7 & & 20.8 & 17.0 & & 23.3 & 18.7 & & 20.6 & 19.4 & & 25.2 & 17.4 & \\
\hline $\mathrm{SD}$ & 18 & 13.3 & & 15.4 & 15.4 & & 17.9 & 15.4 & & 15.8 & 16.3 & & 17.4 & 12 & \\
\hline $\begin{array}{l}\text { Number } \\
\text { retrieved LN }\end{array}$ & & & 0.309 & & & 0.515 & & & 0.763 & & & 0.775 & & & 0.085 \\
\hline Mean & 56.1 & 53.5 & & 54.9 & 52.7 & & 56.4 & 55.4 & & 51.5 & 52.5 & & 55.8 & 47.2 & \\
\hline SD & 17.7 & 19 & & 16.6 & 17.1 & & 16.8 & 22.3 & & 15.7 & 16.3 & & 17.2 & 16.4 & \\
\hline $\mathrm{T}$ classification & & & $<0.001$ & & & 0.011 & & & 0.037 & & & 0.553 & & & $<0.001$ \\
\hline $\mathrm{T} 2$ & $2(2.3)$ & $5(4.1)$ & & $2(3.7)$ & $3(5.9)$ & & $2(3.5)$ & $2(3.0)$ & & $2(3.8)$ & $1(2.3)$ & & $2(2.4)$ & $0(0)$ & \\
\hline $\mathrm{T} 3$ & $6(6.9)$ & $24(19.5)$ & & $2(3.7)$ & $7(13.7)$ & & $4(7.0)$ & $14(20.9)$ & & $4(7.5)$ & $3(6.8)$ & & $5(5.9)$ & $7(50.0)$ & \\
\hline $\mathrm{T} 4 \mathrm{a}$ & $67(77.0)$ & $92(74.8)$ & & 43 (79.6) & 41 (80.4) & & $44(77.2)$ & $49(73.1)$ & & $40(75.5)$ & $38(86.4)$ & & $66(77.6)$ & $7(50.0)$ & \\
\hline $\mathrm{T} 4 \mathrm{~b}$ & $12(13.8)$ & $2(1.6)$ & & $7(13.0)$ & $0(0)$ & & $7(12.3)$ & $2(3.0)$ & & $7(13.2)$ & $2(4.5)$ & & $12(14.1)$ & $0(0)$ & \\
\hline $\mathrm{N}$ classification & & & 0.065 & & & 0.583 & & & 0.491 & & & 0.809 & & & $>0.999$ \\
\hline N1 & $2(2.3)$ & $6(4.9)$ & & $2(3.7)$ & $1(1.9)$ & & $2(3.5)$ & $3(4.5)$ & & $1(1.9)$ & $2(4.5)$ & & $2(2.4)$ & $0(0)$ & \\
\hline $\mathrm{N} 2$ & $8(9.2)$ & $24(19.5)$ & & $8(14.8)$ & 11 (21.6) & & $6(10.5)$ & $12(17.9)$ & & $7(13.2)$ & $5(11.4)$ & & $8(9.4)$ & $1(7.1)$ & \\
\hline N3 & 77 (88.5) & $91(75.6)$ & & 44 (81.5) & $39(76.5)$ & & $49(86.0)$ & $52(77.6)$ & & $45(84.9)$ & $37(84.1)$ & & 75 (88.2) & $13(92.9)$ & \\
\hline TNM stage & & & 0.001 & & & 0.059 & & & 0.013 & & & 0.237 & & & 0.001 \\
\hline Stage IIA & $0(0)$ & $1(0.8)$ & & $0(0)$ & $1(2.0)$ & & $0(0)$ & $0(0)$ & & $0(0)$ & $0(0)$ & & $0(0)$ & $0(0)$ & \\
\hline Stage IIB & $3(3.5)$ & $4(3.2)$ & & $3(5.5)$ & $1(2.0)$ & & $3(5.3)$ & $2(3.0)$ & & $3(5.7)$ & $1(2.3)$ & & $3(3.5)$ & $0(0)$ & \\
\hline Stage IIIA & $0(0)$ & $13(10.6)$ & & $0(0)$ & $4(7.8)$ & & $0(0)$ & $8(11.9)$ & & $0(0)$ & $3(6.8)$ & & $0(0)$ & $0(0)$ & \\
\hline Stage IIIB & 11 (12.6) & $27(22.0)$ & & $7(13.0)$ & 11 (21.6) & & $7(12.3)$ & 13 (19.4) & & $7(13.2)$ & $4(9.1)$ & & $10(11.8)$ & $8(57.1)$ & \\
\hline Stage IIIC & 73 (93.9) & $78(63.4)$ & & 44 (81.5) & 34 (66.6) & & $47(82.4)$ & $44(65.7)$ & & $43(81.1)$ & $36(81.8)$ & & $72(84.7)$ & $6(42.9)$ & \\
\hline
\end{tabular}

Abbreviations: LN, lymph node; SD, standard deviation; LC, lesser curvature; GC, greater curvature; AW, anterior wall; PW, posterior wall; LV, lympho-vascular. * $P$-values were calculated from Student's $t$-test or $\chi^{2}$ (Fisher's exact) test for continuous or categorical factors, respectively. 
Table 3: Recurrence patterns

\begin{tabular}{|c|c|c|c|c|c|c|}
\hline Groups & Locoregional & Hematogenous & Distant LN & Peritoneal & Mixed & $\boldsymbol{P}$ \\
\hline $\mathrm{LN \# 10+}(n=64)$ & $3(4.7)^{*}$ & $8(12.5)$ & $4(6.3)$ & $37(57.8)$ & $12(18.8)$ & \multirow{2}{*}{0.389} \\
\hline $\mathrm{LN \# 10-}(n=212)$ & $5(2.4)$ & $36(17.0)$ & $21(9.9)$ & $125(59.0)$ & $25(11.8)$ & \\
\hline $\mathrm{LN} \# 10+(n=64)$ & $3(4.7)$ & $8(12.5)$ & $4(6.3)$ & $37(57.8)$ & $12(18.8)$ & \multirow{2}{*}{0.506} \\
\hline LN\#10-AnyN2+ $(n=87)$ & $2(2.3)$ & $13(14.9)$ & $12(13.8)$ & $48(55.2)$ & $12(13.8)$ & \\
\hline LN\#10+LN\#8- $(n=37)$ & $2(5.4)$ & $4(10.8)$ & $2(5.4)$ & $22(59.5)$ & $7(18.9)$ & \multirow{2}{*}{0.596} \\
\hline 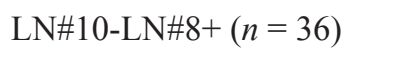 & $1(2.8)$ & $5(13.9)$ & $6(16.7)$ & $19(52.8)$ & $5(13.9)$ & \\
\hline LN\#10+LN\#9- $(n=41)$ & $3(7.3)$ & $7(17.1)$ & $2(4.9)$ & $22(53.7)$ & $7(17.1)$ & \multirow{2}{*}{0.134} \\
\hline 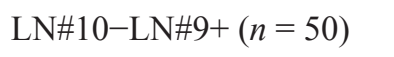 & $0(0)$ & $10(20.0)$ & $9(18.0)$ & $24(48.0)$ & $7(14.0)$ & \\
\hline 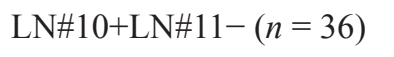 & $0(0)$ & $5(13.9)$ & $3(8.3)$ & $23(63.9)$ & $5(13.9)$ & \multirow{2}{*}{0.712} \\
\hline 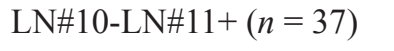 & $1(2.7)$ & $3(8.1)$ & $6(16.2)$ & $22(59.5)$ & $5(13.5)$ & \\
\hline 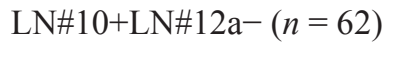 & $3(4.8)$ & $7(11.3)$ & $4(6.5)$ & $37(59.7)$ & $11(17.7)$ & \multirow{2}{*}{0.085} \\
\hline 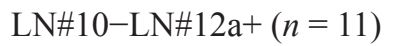 & $0(0)$ & $3(27.3)$ & $0(0)$ & $3(27.3)$ & $5(45.5)$ & \\
\hline
\end{tabular}

*Values in parentheses are percentages.

of splenic hilar LN metastasis with metastasis to other extraperigastric LNs, as well as distant metastasis, in terms of survival and recurrence patterns. In this comparison, the extraperigastric LN metastasis groups (LN \#8a, \#9, \#11, and \#12a, according to JGCA classification [7], which did not have hilar LN metastasis, showed similar long-term prognoses and recurrence patterns to patients with hilar LN metastasis. Although, there was no patient with metastasis to LN \#10 without any extraperigastric LN metastasis, which might indicate splenic hilar LN was the farthest regional LN or boundary LN between the extraperigastric and distant LN, the survival between the patients with metastasis to LN \#10 and those with metastasis to any extraperigastric but not to LN \#10 metastasis did not significantly different. Additionally, the estimated therapeutic index value for splenic hilar LN dissection

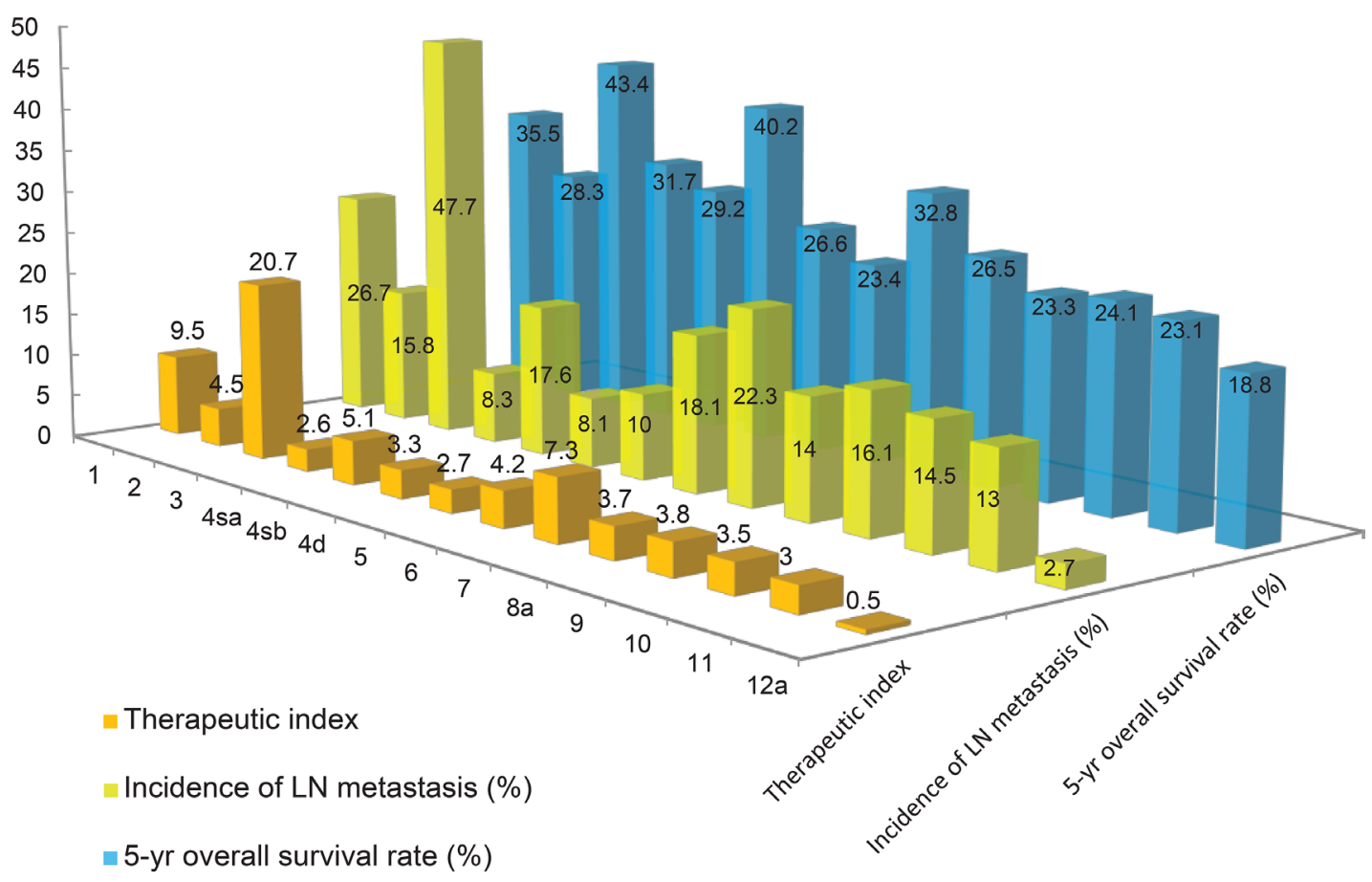

Figure 3: Estimated benefit of lymph node (LN) dissection by calculating therapeutic index. Therapeutic index was calculated by multiplying the frequency of metastases by 5 -year survival rates for individuals with nodal involvement at that specific station, regardless of nodal metastases to any other LN station. 
(3.5) was comparable to values for extraperigastric LN dissection (0.5-3.8). In support of these results, other studies have also reported similar therapeutic index values, ranging from 2.4-3.8, for $\mathrm{LN}$ \#10 dissection of upper third gastric cancer $[11,21]$. Taken together, these findings suggest that splenic hilar LNs should indeed continue to be classified as a regional LN group.

A recent Japanese multicenter prospective study (JCOG 0110) that examined splenectomy versus spleen-preservation during total gastrectomy for clinically advanced gastric cancer revealed no benefit of splenectomy in terms of operative safety and survival [22]; however, the study excluded tumors of the greater curvature, although these tumors are generally candidates for splenic hilar LN dissection. Thus, the study included clinically advanced gastric cancer patients who had little possibility of splenic hilar LN metastasis. Also, a large number of patients with pathologic T1 or N0 cancer was also included. Therefore, from these results alone, the actual therapeutic impact of splenic hilar LN dissection on advanced gastric cancer in patients with LN \#10 involvement would be difficult to determine. In our study, however, we focused explicitly on the prognosis of splenic hilar LN metastasis, demonstrating acceptable survival and recurrence as well as a similar prognostic impact for splenic hilar LN dissection in comparison to dissection of metastases to other extraperigastric LNs.

Although current guidelines indicate D2 LN dissection, including splenic hilar LN dissection, for advanced (T2 or more advanced) gastric cancer during total gastrectomy, alterations of these indications to reflect tumor characteristics warrants discussion. As shown in this study, as well as in previous reports, significantly larger tumors, Borrmann type IV tumors, and advanced stage tumors involving the greater curvature or entire stomach were prominent in the hilar LN metastasis group [10-13, $15,16,23]$. In addition, $96.5 \%(84 / 87)$ of patients who had hilar LN metastasis were staged IIIB or IIIC in the current study, while only $1.1 \%(3 / 267)$ of patients with hilar LN metastasis were staged IB to IIIA. A recent randomized controlled trial revealed no hilar LN metastasis in stage IIIA tumors or less advanced tumors that were staged according to the 6th TNM staging system, similar to our study [24]. Therefore, tumors not involving the greater curvature of the stomach that are small in size and of earlier stages may not warrant hilar LN dissection.

In our study, the indications for splenic hilar LN dissection likely varied among surgeons. In addition, the indications for either splenectomy or spleen-preserving hilar LN dissection could not be discerned, as this decision was made at the surgeon's discretion. The splenectomy group consisted of patients who had tumors of larger size at the greater curvature or circular location and were of advanced $\mathrm{T}$ classification/TNM stage. This group also included patients with a larger number of metastatic LNs (Table 4, Supplement). These characteristics reflected the poor survival outcomes in the splenectomy group (Figure 4, Supplement). Also, picking up LN \#10 after spleen-preserving hilar LN dissection is difficult, although one surgeon who participated in the operation picked up each station just after the operation before sending it to the pathologist. As a potential consequence thereof, we obtained a significant difference in the number of retrieved LNs between splenectomy and spleen-preservation. Moreover, although we typically divide LN bearing tissue around the bifurcation of the upper or lower polar splenic artery from the main splenic artery to discriminate LN \#10 from LN \#11d, it can be difficult to divide them clearly. Additionally, there is the possibility that the actual number of retrieved LNs after spleen-preserving hilar LN dissection would be less, because posterior aspects of splenic vessels can be difficult to reach. This study also did not account for postoperative adjuvant chemotherapy, which may have an impact on patient survival. In general, patients with stage II or higher disease receive postoperative chemotherapy in accordance with our institution's standard postoperative care. Despite these limitations, this study included a large number of patients who underwent standard D2
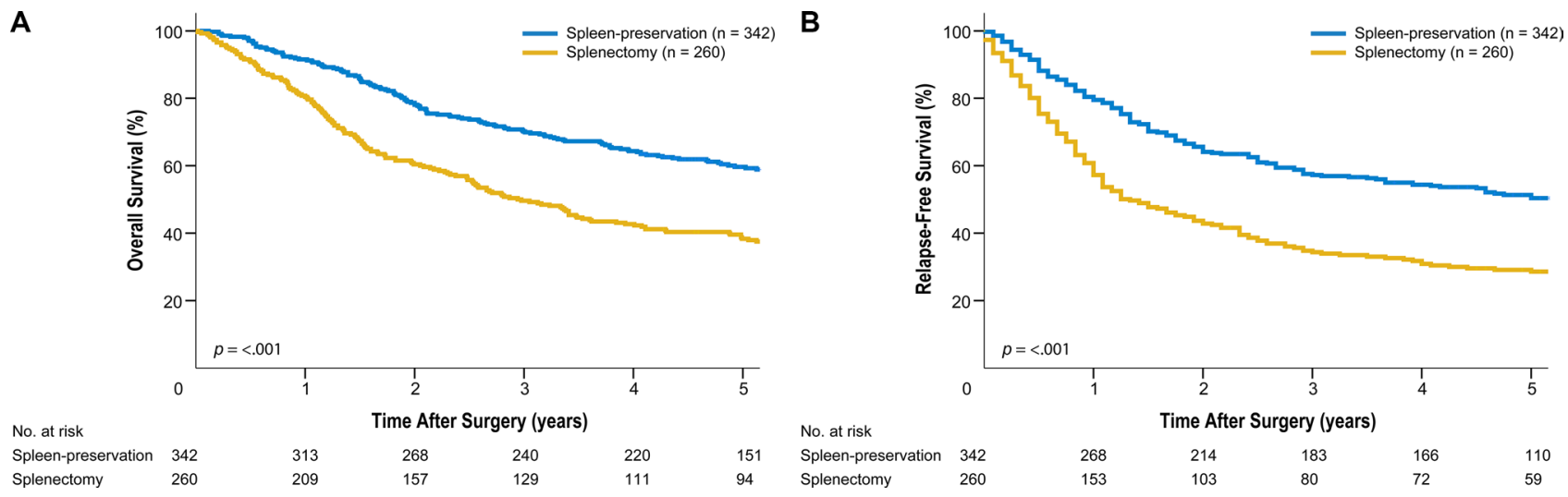

Figure 4: (Supplement). Kaplan-Meier survival curves for patients who underwent spleen-preserving hilar lymph node dissection and splenectomy. (A) Overall survival. (B) Relapse-free survival. 
Table 4: (Supplement)

\begin{tabular}{|c|c|c|c|c|c|c|c|}
\hline \multirow[b]{2}{*}{ Variable } & \multicolumn{3}{|c|}{ Spleen-preservation $(n=342)$} & \multicolumn{3}{|c|}{ Splenectomy $(n=260)$} & \multirow[b]{2}{*}{$P^{*}$} \\
\hline & $\begin{array}{c}\text { No. of } \\
\text { Patients }\end{array}$ & & $\%$ & $\begin{array}{c}\text { No. of } \\
\text { Patients }\end{array}$ & & $\%$ & \\
\hline Age, years & & & & & & & 0.467 \\
\hline Mean & & 56.0 & & & 56.8 & & \\
\hline $\mathrm{SD}$ & & 12.4 & & & 12.1 & & \\
\hline Sex & & & & & & & 0.377 \\
\hline Male & 234 & & 68.4 & 169 & & 65.0 & \\
\hline Female & 108 & & 31.6 & 91 & & 35.0 & \\
\hline Histologic type & & & & & & & 0.634 \\
\hline Differentiated & 86 & & 25.1 & 61 & & 23.5 & \\
\hline Undifferentiated & 256 & & 74.9 & 199 & & 76.5 & \\
\hline Tumor size, $\mathrm{cm}$ & & & & & & & $<0.001$ \\
\hline Mean & & 6.1 & & & 7.5 & & \\
\hline SD & & 3.4 & & & 3.8 & & \\
\hline Location & & & & & & & 0.009 \\
\hline $\mathrm{LC}$ & 172 & & 50.3 & 116 & & 44.6 & \\
\hline $\mathrm{GC}$ & 30 & & 8.8 & 36 & & 13.8 & \\
\hline AW & 51 & & 14.9 & 39 & & 15.0 & \\
\hline PW & 84 & & 24.6 & 54 & & 20.8 & \\
\hline Circular & 5 & & 1.4 & 15 & & 5.8 & \\
\hline Gross type & & & & & & & 0.203 \\
\hline Borrmann I & 21 & & 6.2 & 17 & & 6.5 & \\
\hline Borrmann II & 63 & & 18.4 & 61 & & 23.5 & \\
\hline Borrmann III & 179 & & 52.3 & 111 & & 42.7 & \\
\hline Borrmann IV & 75 & & 21.9 & 68 & & 26.1 & \\
\hline Borrmann V & 4 & & 1.2 & 3 & & 1.2 & \\
\hline LV invasion & & & & & & & 0.033 \\
\hline negative & 127 & & 37.1 & 75 & & 28.8 & \\
\hline positive & 215 & & 62.9 & 185 & & 71.2 & \\
\hline Number of metastatic LNs & & & & & & & $<0.001$ \\
\hline Mean & & 8.0 & & & 11.9 & & \\
\hline $\mathrm{SD}$ & & 11.4 & & & 15.2 & & \\
\hline Number of retrieved LNs & & & & & & & 0.231 \\
\hline Mean & & 52.1 & & & 53.8 & & \\
\hline $\mathrm{SD}$ & & 17.4 & & & 18.5 & & \\
\hline \multicolumn{8}{|l|}{ LN \#10 involvement } \\
\hline positive & 31 & & 9.1 & 56 & & 21.5 & \\
\hline negative & 311 & & 90.9 & 204 & & 78.5 & \\
\hline Number of metastatic LNs at LN \#10 & & & & & & & $<0.001$ \\
\hline
\end{tabular}


Mean

SD

Number of retrieved LNs at LN \#10

Mean

SD

$\mathrm{T}$ classification

T2

T3

$\mathrm{T} 4 \mathrm{a}$

$\mathrm{T} 4 \mathrm{~b}$

$\mathrm{N}$ classification

N0

N1

N2

N3

TNM stage

Stage IB

Stage IIA

Stage IIB

Stage IIIA

Stage IIIB

Stage IIIC
0.2

0.6

2.0

2.1
0.6

1.7

$<0.001$

3.1

3.4

8.1

10.4

73.8

7.7

0.092

21.2

11.9

18.8

48.1

$<0.001$

4.2

3.1

16.5

13.1

18.9

44.2

Comparison of clinicopathologic factors between spleen-preserving hilar LN dissection and splenectomy patient groups.

LN dissection by experienced surgeons at a high-volume medical center. The results are significant because these findings encompass both therapeutic and prophylactic LN dissection for the treatment of proximal advanced gastric cancer. We discovered that patients with advanced gastric cancer with splenic hilar LN metastasis experience similar survival to those with other extraperigastric LN metastasis. These results suggest that splenic hilar LNs should be regarded as a regional LN group during total gastrectomy for the treatment of proximal advanced gastric cancer.

\section{MATERIALS AND METHODS}

Using a prospective database, we identified 2,453 patients who underwent total gastrectomy for gastric adenocarcinoma from 2000 to 2010 at Severance Hospital, Yonsei University Medical Center. Individual clinical and pathologic tumor characteristics, as well as short- and longterm patient outcomes, were retrieved. From the original cohort, 1,694 patients were excluded: 93 patients received preoperative chemotherapy with or without radiotherapy, 627 patients had T1 tumors, 906 patients did not undergo D2 $\mathrm{LN}$ dissection, and 68 patients had no information on splenic hilar LN metastasis (Figure 5). The final study population comprised 759 patients, among which 602 underwent curative total gastrectomy with $\mathrm{D} 2 \mathrm{LN}$ dissection. Of these patients, 87 out of 602 had splenic hilar LN metastasis and 157 had distant metastasis (M1) who received palliative total gastrectomy either splenic hilar lymph node dissection or not. Of all 157 patients with distant metastasis, 112 peritoneal metastases or Krukenberg tumors, 32 hematogenous metastases, six distant LNs metastases, and seven mixed metastases were included. Clinicopathologic characteristics, including age, sex, histologic differentiation, tumor size, location, gross type, lympho-vascular invasion, number of metastatic and retrieved LNs, and tumor-nodemetastasis (TNM) stages, were included in the analyses. This retrospective study was approved by the Institutional Review Board of Severance Hospital, Yonsei University College of Medicine (4-2015-0951).

\section{Extent of lymphadenectomy}

Total gastrectomy with D2 LN dissection was performed in accordance with the Japanese Gastric Cancer Association (JGCA) classification guidelines [7]. 


\section{Indications for splenectomy or spleen-preserving hilar LN dissection}

At our institution, splenectomy during total gastrectomy with D2 LN dissection is indicated for gastric cancers with definite splenic hilar LN enlargement or direct invasion to the gastrosplenic ligament or the spleen. Spleen-preserving hilar LN dissection is indicated for gastric cancers with no serosal involvement and no evidence of gross LN metastasis along the splenic artery or splenic hilum during preoperative and intraoperative evaluation $[17,25]$. We previously published our standard procedures for performing open or minimally invasive total gastrectomy with D2 LN dissection $[25,26]$.

\section{Indications for minimally invasive surgery}

Patients with preoperative diagnosis of suspicious proper muscle invasion were indicated for total gastrectomy with D2 LN dissection, using either conventional laparoscopy or a robotic surgical system, since 2003 and 2005, respectively. Patients with evidence of serosal involvement or patients with any evidence of gross LN metastasis along the splenic artery or hilum were not generally considered to be indicated for minimally invasive surgery. All patients suitable for minimally invasive surgery were informed about procedures, including open gastrectomy and the risks and benefits of each procedure. All patients were allowed to select the type of operation that they would undergo, and all gave informed consent for the surgical method at the time of operation.

\section{Prognostic impact of splenic hilar LN metastasis}

To evaluate the impact of splenic hilar LN metastasis on prognosis in gastric cancer patients, the survival of patients with metastasis to splenic hilar LNs (LN station \#10) was compared to that of patients with metastasis to other extraperigastric LNs (e.g., LN stations $\# 8$ a, \#9, \#11, or \#12a) who did not concurrently have splenic hilar LN metastasis. For example, patients with metastasis to LN station \#10 without metastasis to LN

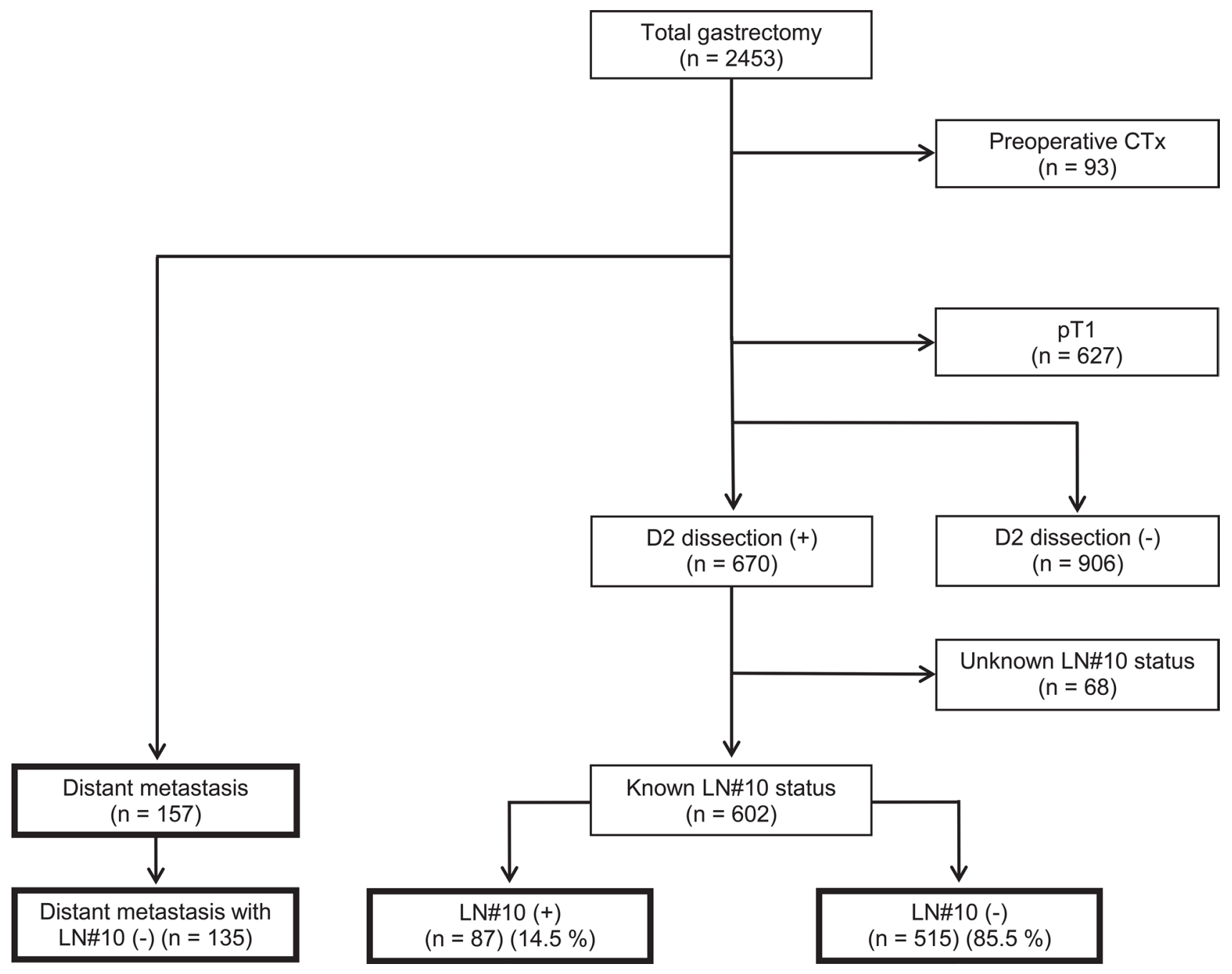

Figure 5: Study profile. 
station \#12a were compared to patients with metastasis to LN station \#12a without metastasis to LN station \#10. We also compared survival of the patients with metastasis to LN station \#10 without metastasis to any extraperigastric LN to any extraperigastric LN station without LN station \#10 metastasis. The overall survival curve of the splenic hilar metastasis group was compared to that of patients with distant metastasis $(n=157)$ and patients with distant metastasis without splenic hilar LN metastasis $(n=135)$.

\section{Estimated therapeutic index of splenic hilar LN dissection for gastric cancer}

The estimated therapeutic index was first proposed as a means to estimate the benefit of removing an LN during surgery [21]. The index is calculated by multiplying the incidence of metastases by 5-year survival rates for individuals with nodal involvement at that specific station, regardless of nodal metastases to any other LN station.

\section{Patterns of recurrence}

Patterns of recurrence were defined as locoregional, hematogenous, distant, peritoneal, and mixed, as in previous reports $[27,28]$.

\section{Statistical analysis}

Clinicopathologic and short- and long-term operative results, including recurrence and survival, were analyzed using the Statistical Package for Social Sciences software, version 20.0 (IBM, Armonk, NY, USA). During the study period, patients were followed from the date of surgery until December 31, 2014 or their death. Overall survival was calculated from the date of operation to the last follow-up or death from any cause. Relapse-free survival was calculated from the date of operation to recurrence of gastric cancer or death from any cause. The date of recurrence was recorded as the day on which recurrence was confirmed by any imaging modality or tissue confirmation. Patients not experiencing the relevant end points were censored at last follow-up. Five-year overall survival and relapsefree survival were calculated using the Kaplan-Meier method, and differences in these rates between groups were examined using the log-rank test. Categorical and continuous variables were analyzed by the $\chi^{2}$ or Fisher's exact and Student's $t$-test, respectively. $P$-values $<0.05$ (two-sided) were considered statistically significant.

\section{Abbreviations}

LN = lymph node; JGCA = Japanese Gastric Cancer Association; JCOG = Japan Clinical Oncology Group.

\section{Authors' contributions}

Taeil Son and In Gyu Kwon contributed equally to this work. TS, IGK, and WJH designed the study. TS,
IGK, and JHL collected the data. TS, IGK, HIK, and WJH conducted the statistical analyses. TS, IGK, and WJH wrote the paper. JHL, YYC, JHC, and SHN critically revised subsequent drafts. All authors read and approved the submitted version.

\section{ACKNOWLEDGMENTS}

We would like to thank Anthony Thomas Milliken, ELS (Editing Synthase, Seoul, Korea) for his assistance with editing the manuscript. We also acknowledge the assistance of BioScience Writers, LLC (Houston, TX, USA) with copyediting and correction of English language usage.

\section{CONFLICTS OF INTEREST}

All authors declare no conflicts of interest.

\section{FUNDING}

All authors have completed the disclosure declaration, and none of the authors or their immediate family members report a conflicting financial interest. This study was supported by a grant from the National R\&D Program for Cancer Control, Ministry of Health \& Welfare, Republic of Korea (1320270).

\section{REFERENCES}

1. Torre LA, Bray F, Siegel RL, Ferlay J, Lortet-Tieulent J, Jemal A. Global cancer statistics, 2012. CA Cancer J Clin. 2015; 65:87-108.

2. Kong SH, Park DJ, Lee HJ, Jung HC, Lee KU, Choe KJ, Yang HK. Clinicopathologic features of asymptomatic gastric adenocarcinoma patients in Korea. Jpn J Clin Oncol. 2004; 34:1-7.

3. Kim YG, Kong SH, Oh SY, Lee KG, Suh YS, Yang JY, Choi J, Kim SG, Kim JS, Kim WH, Lee HJ, Yang HK. Effects of screening on gastric cancer management: comparative analysis of the results in 2006 and in 2011. J Gastric Cancer. 2014; 14:129-134.

4. Everett SM, Axon AT. Early gastric cancer in Europe. Gut. 1997; 41:142-150.

5. Karve S, Lorenzo M, Liepa AM, Hess LM, Kaye JA, Calingaert B. Treatment Patterns, Costs, and Survival among Medicare-Enrolled Elderly Patients Diagnosed with Advanced Stage Gastric Cancer: Analysis of a Linked Population-Based Cancer Registry and Administrative Claims Database. J Gastric Cancer. 2015; 15:87-104.

6. Blot WJ, Devesa SS, Kneller RW, Fraumeni JF Jr. Rising incidence of adenocarcinoma of the esophagus and gastric cardia. JAMA. 1991; 265:1287-1289.

7. Japanese gastric cancer treatment guidelines 2014 (ver. 4). Gastric Cancer. 2016; 20:1-19. 
8. Ajani JA, Bentrem DJ, Besh S, D'Amico TA, Das P, Denlinger C, Fakih MG, Fuchs CS, Gerdes H, Glasgow RE, Hayman JA, Hofstetter WL, Ilson DH, et al. Gastric cancer, version 2.2013: featured updates to the NCCN Guidelines. J Natl Compr Canc Netw. 2013; 11:531-546.

9. Lee JH, Kim JG, Jung HK, Kim JH, Jeong WK, Jeon TJ, Kim JM, Kim YI, Ryu KW, Kong SH, Kim HI, Jung HY, Kim YS, et al. Synopsis on clinical practice guideline of gastric cancer in Korea: an evidence-based approach. Korean J Gastroenterol. 2014; 63:66-81.

10. Mönig SP, Collet PH, Baldus SE, Schmackpfeffer K, Schröder W, Thiele J, Dienes HP, Hölscher AH. Splenectomy in proximal gastric cancer: frequency of lymph node metastasis to the splenic hilus. J Surg Oncol. 2001; 76:89-92.

11. Kunisaki C, Makino H, Suwa H, Sato T, Oshima T, Nagano Y, Fujii S, Akiyama H, Nomura M, Otsuka Y, Ono HA, Kosaka T, Takagawa $R$, et al. Impact of splenectomy in patients with gastric adenocarcinoma of the cardia. J Gastrointest Surg. 2007; 11:1039-1044.

12. Maruyama K, Gunvén $\mathrm{P}$, Okabayashi K, Sasako M, Kinoshita T. Lymph node metastases of gastric cancer. General pattern in 1931 patients. Ann Surg. 1989; 210:596-602.

13. Shin SH, Jung H, Choi SH, An JY, Choi MG, Noh JH, Sohn TS, Bae JM, Kim S. Clinical significance of splenic hilar lymph node metastasis in proximal gastric cancer. Ann Surg Oncol. 2009; 16:1304-1309.

14. Zhu GL, Sun Z, Wang ZN, Xu YY, Huang BJ, Xu Y, Zhu Z, $\mathrm{Xu} \mathrm{HM}$. Splenic hilar lymph node metastasis independently predicts poor survival for patients with gastric cancers in the upper and/or the middle third of the stomach. J Surg Oncol. 2012; 105:786-792.

15. Maehara Y, Moriguchi S, Yoshida M, Takahashi I, Korenaga D, Sugimachi K. Splenectomy does not correlate with length of survival in patients undergoing curative total gastrectomy for gastric carcinoma. Univariate and multivariate analyses. Cancer. 1991; 67:3006-3009.

16. Yu W, Choi GS, Chung HY. Randomized clinical trial of splenectomy versus splenic preservation in patients with proximal gastric cancer. Br J Surg. 2006; 93:559-563.

17. Lee KY, Noh SH, Hyung WJ, Lee JH, Lah KH, Choi SH, Min JS. Impact of splenectomy for lymph node dissection on long-term surgical outcome in gastric cancer. Ann Surg Oncol. 2001; 8:402-406.
18. Hyung WJ, Lim JS, Song J, Choi SH, Noh SH. Laparoscopic spleen-preserving splenic hilar lymph node dissection during total gastrectomy for gastric cancer. J Am Coll Surg. 2008; 207:e6-11.

19. Ikeguchi M, Kaibara N. Lymph node metastasis at the splenic hilum in proximal gastric cancer. Am Surg. 2004; 70:645-648.

20. Edge S, Byrd DR, Compton CC, Fritz AG, Greene FL, Trotti A. American Joint Committee on Cancer (AJCC). AJCC cancer staging manual. 7th ed. New York. Springer, 2010.

21. Sasako M, McCulloch P, Kinoshita T, Maruyama K. New method to evaluate the therapeutic value of lymph node dissection for gastric cancer. Br J Surg. 1995; 82:346-351.

22. Sano T, Sasako M, Mizusawa J, Yamamoto S, Katai H, Yoshikawa T, Nashimoto A, Ito S, Kaji M, Imamura H, Fukushima N, Fujitani K. Randomized Controlled Trial to Evaluate Splenectomy in Total Gastrectomy for Proximal Gastric Carcinoma. Ann Surg. 2017; 265:277-283.

23. Koga S, Kaibara N, Kimura O, Nishidoi H, Kishimoto H. Prognostic significance of combined splenectomy or pancreaticosplenectomy in total and proximal gastrectomy for gastric cancer. Am J Surg. 1981; 142:546-550.

24. Csendes A, Burdiles P, Rojas J, Braghetto I, Diaz JC, Maluenda F. A prospective randomized study comparing D2 total gastrectomy versus D2 total gastrectomy plus splenectomy in 187 patients with gastric carcinoma. Surgery. 2002; 131:401-407.

25. Oh SJ, Hyung WJ, Li C, Song J, Kang W, Rha SY, Chung HC, Choi SH, Noh SH. The effect of spleen-preserving lymphadenectomy on surgical outcomes of locally advanced proximal gastric cancer. J Surg Oncol. 2009; 99:275-280.

26. Son T, Lee JH, Kim YM, Kim HI, Noh SH, Hyung WJ. Robotic spleen-preserving total gastrectomy for gastric cancer: comparison with conventional laparoscopic procedure. Surg Endosc. 2014; 28:2606-2615.

27. Yoo CH, Noh SH, Shin DW, Choi SH, Min JS. Recurrence following curative resection for gastric carcinoma. $\mathrm{Br}$ J Surg. 2000; 87:236-242.

28. Song J, Lee HJ, Cho GS, Han SU, Kim MC, Ryu SW, Kim W, Song KY, Kim HH, Hyung WJ. Recurrence following laparoscopy-assisted gastrectomy for gastric cancer: a multicenter retrospective analysis of 1,417 patients. Ann Surg Oncol. 2010; 17:1777-1786. 